\section{ECONOMICS}

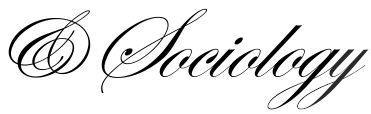

\author{
Carla Blázquez-Fernández, \\ University of Cantabria, \\ Santander, Spain, \\ E-mail: carla.blazquez@unican.es
}

\section{David Cantarero-Prieto, University of Cantabria, Santander, Spain, \\ E-mail: david.cantarero@unican.es}

Marta Pascual-Sáez,

University of Cantabria,

Santander, Spain,

E-mail:marta.pascual@unican.es

Received: September, 2016

1st Revision: October, 2016

Accepted: December, 2016

DOI: $10.14254 / 2071-$

789X.2017/10-1/1

JEL Classification: I10, I18
Blázquez-Fernández, C., Cantarero-Prieto, D., Pascual-Sáez, M. (2017), Patient Cross-Border Mobility: New Findings and Implications in Spanish Regions, Economics and Sociology, Vol. 10, No 1, pp. 11-21. DOI: 10.14254/2071789X.2017/10-1/1

\title{
PATIENT CROSS-BORDER MOBILITY: NEW FINDINGS AND IMPLICATIONS IN SPANISH REGIONS
}

\begin{abstract}
Spain has a National Health Service with a mixed public-private funded system. In the last decades, a huge effort has gone into reducing barriers to patient migration. We estimate a panel data based on a gravity model of migration since the process of health care decentralization has been completed in Spain. Our empirical results show that income is one of the most important drivers in explaining mobility as well as supply variables. Individual characteristics are not among the main factors for mobility. Besides, it is demonstrated there is a quality-driven mobility in Spain. However, there was no significant difference in the influence on patients' mobility between those living in the North of the country and the Mediterranean regions. The empirical results also suggest that current regional health policies in Spain, that explain patients' mobility, should be associated with greater funding system.
\end{abstract}

Keywords: health care, patient migration, panel data, Spain.

\section{Introduction}

Diverse studies have analysed the relationship between socioeconomic factors and health (Arrow, 1963; Grossman, 1972 a, b). Nevertheless, demand for health care is based on the individual's perception of medical symptoms and the incentive towards action (Rivera, 2004). The key point here is those factors related to patients' health care mobility in which it is essential to take into account that nowadays they are better informed. Mainly, the growth of the use of new technologies is having an important effect on individuals' health knowledge and behaviour. In any case, the final decision of an individual would be mostly derived from its utility. That is, the number of patients moving from one region to another would be determined by the quality and the distance to the health care service. Then, mobility would happen if and only if the net benefit from going to the other region is higher than the net loss of consuming a quality level different from the desired in the residential one. In this sense, several studies have analysed patient migration (Levaggi and Zanola, 2004; Fabrri and Rabone, 2010; Baker et al., 2014; Balia et al., 2014; Lunt and Mannion, 2014; Brekke et al., 2015) although major challenges remain, such as to delimitate the international state-of-theart concerning patient mobility across European member states (Frischhut and Levaggi, 2015). For example, evidence about patient mobility phenomenon exists within the National Health Service in the United Kingdom (Exworthy and Peckham, 2006) and also in the Italian 
decentralized health service (Brenna and Spandonaro, 2015). Recent evidence as also showed in Finkelstein, Gentzkow and Williams (2016) that studied the drivers of geographic variation in U.S., using an empirical strategy that exploits migration of Medicare patients to separate the role of demand and supply factors.

Nowadays, most of the recent literature on patient mobility relates to international mobility between national health systems, in some cases even identified as "medical tourism". This increasing finding has been studied under different looks - flow size, conflicting effects, income and health, time periods, internal domestic regulations, reciprocity connections between countries, patient profiles or demographic and equity issues - but applied research on this topic is still needed (Roghman and Zastowny, 1979; Congdon, 2001; Lowe and Sen, 2006; Glinos et al., 2010; Migge and Gilmartin, 2011; Glinos et al., 2012; Lunt et al., 2013; De Mello-Sampayo, 2014; Lunt and Mannion, 2014). Although these issues are relevant, go beyond the scope of our study which is going to be based on the well-known determinants of patients' cross-border mobility or induction effects at the regional level.

Regarding the Spanish case, patient mobility across regions understood as crossborder mobility within the country has been studied only before in Cantarero (2006). To be precise, they focus on the period before the decentralization of health care powers has been completed. Using a model of patient migration, the empirical results presented there support the existence of a quality-driven mobility.

Instead of it, in the present paper our objectives are two: (i) to analyse the updated determinants of patient's migration in Spain; and (ii) to determine if the patterns have changed since the decentralization process has been completed. By doing this, the period under study will be 2002-2013.

Particularly, over the sample period, the Spanish National Health Service is characterized by one main feature, the completed decentralization of health care to regions. This process began in 1981 and ended in 2001, according to three different models distinguished among the 17 regions: (i) Two "foral" regions (Basque Country (1987) and Navarre (1991)); (ii) Five regions (Catalonia (1981), Andalusia (1984), Valencian Community (1987), Galicia (1991), and Canary Islands (1994)) kept health powers, but with fiscal responsibility limited; (iii) The remaining regions (Aragon, Asturias, Balearic Islands, Cantabria, Castile-La Mancha, Castile and Leon, Madrid, Extremadura, La Rioja, and Murcia) had no health powers until 2002, which provided all the Spanish regions a larger autonomy in the administration and organization of the healthcare services.

This regionally decentralized tax-funded model, in spite of guaranteeing minimum levels of health care everywhere, implies that the quality and quantity of health care might vary across Spanish regions and patients are entitled to choose a preferred provider of hospital or health care facilities in the whole country. Because Spain can be described as a country with a decentralized model, such configuration can have controversial effects on the efficiency and effectiveness of the healthcare services provided at the regional level, as well as on universalism and equity. That is, there appear differences across regions mainly in complementary supply and coverage of (and access to) some health care programs. Also, in the distribution of hospital beds or the availability of high-tech health care services as it is recently showed it in González López-Valcárcel and Barber (2017).

Therefore, it could derive in these consequences: health care inequalities and health care migration (Lopez-Casasnovas, Costa-Font and Planas, 2005; Costa-Font, 2010). So that, the relevance of this topic of inter-regional mobility also resides in the financing problems derived ("vicious circle"). On the one hand, resources are needed if good quality supply is desired by regions. In fact, many patients despite providing health care services in their regional areas, uses other regions services and this phenomenon decrease in health care utilization in origin regions. On the other hand, if there is no quality and patients migrate, 
regions should pay the others for the consumed services. This result increases competition power of more accepted medical supply and leads other health resources to going out of competition depending on regional financing system (Cuenca and González, 2015).

The remainder of the paper is structured as follows. Section 2 provides a brief description of the data and presents the empirical model. Section 3 contains the empirical results. The final section concludes.

\section{Materials and methods}

This research uses data that have been derived from different sources of information: the Spanish National Institute of Statistics (www.ine.es), IVIE-BBVA (http://www.ivie.es/es/) and Eurostat (http://ec.europa.eu/eurostat). Hence, our work is based on a panel dataset for the seventeen Spanish regions over the period 2002-2013 (latest available data for a balanced panel).

It is interesting to remember that in Spain, since 1978 a centralized state has turned into a decentralized one but with fiscal responsibility limited. After that, the regions started to get health powers and in 2011 all of them achieve them. Thus, we have considered the period 2002-2013 where all the autonomous communities in Spain had health powers.

As the recent literature suggests, variables represent regional mobility, quality and environmental factors. Table 1 shows an overview of key variables and sources of information.

Table 1. Variables and definitions

\begin{tabular}{|c|c|c|}
\hline Variable & Definition & Source \\
\hline$M O B$ & $\begin{array}{l}\text { Net Balance between the inflow of patients } \\
\text { from region } j \text { to the rest of Spain and the outflow } \\
\text { from region } j \text { to the rest of Spain. }\end{array}$ & $\begin{array}{l}\text { Spanish National Institute } \\
\text { of Statistics (INE). }\end{array}$ \\
\hline GDP & $\begin{array}{l}\text { Per Capita Gross Domestic Product (constant } \\
\text { euros). }\end{array}$ & $\begin{array}{l}\text { Spanish National Institute } \\
\text { of Statistics (INE). }\end{array}$ \\
\hline POP65 & $\begin{array}{l}\text { Ratio of people aged } 65 \text { and over (dependence } \\
\text { indicator). }\end{array}$ & $\begin{array}{l}\text { Spanish National Institute } \\
\text { of Statistics (INE). }\end{array}$ \\
\hline CHILDREN & Ratio of people aged 0-14 years. & $\begin{array}{l}\text { Spanish National Institute } \\
\text { of Statistics (INE). }\end{array}$ \\
\hline YOUNG-ADULTS & Ratio of people aged 20-39 years. & $\begin{array}{l}\text { Spanish National Institute } \\
\text { of Statistics (INE). }\end{array}$ \\
\hline MATURE-ADULTS & Ratio of people aged $40-59$ years. & $\begin{array}{l}\text { Spanish National Institute } \\
\text { of Statistics (INE). }\end{array}$ \\
\hline OLD-YOUNG & Ratio of people aged $60-74$ years. & $\begin{array}{l}\text { Spanish National Institute } \\
\text { of Statistics (INE). }\end{array}$ \\
\hline PCHCE & $\begin{array}{l}\text { Per Capita Health Care Expenditure (constant } \\
\text { euros). }\end{array}$ & Ivie-BBVA. \\
\hline BEDS & $\begin{array}{l}\text { Available number of beds per hundred thousand } \\
\text { inhabitants. }\end{array}$ & Eurostat. \\
\hline$M D$ & $\begin{array}{l}\text { Medical doctors per hundred thousand } \\
\text { inhabitants. }\end{array}$ & Eurostat. \\
\hline NORTH & $\begin{array}{l}1 \text { if the region is sited on the North of Spain: } \\
\text { Asturias, Cantabria, Galicia and Basque Country. }\end{array}$ & Authors' elaboration. \\
\hline MEDITERRANEAN & $\begin{array}{l}1 \text { if the region is Mediterranean: Andalusia, } \\
\text { Balearic Islands, Canary Islands, Catalonia, } \\
\text { Valencian Community and Murcia. }\end{array}$ & Authors' elaboration. \\
\hline
\end{tabular}

Source: Authors' elaboration. 
If we focus the analysis on our dependent variable $(M O B)$ defined as net balance between the inflow of patients from one region to the rest of country and the outflow from this region to the rest of the country, both Table 2 and Figure 1 provide a general overview by Spanish regions. It should be highlighted that the net mobility is extremely high for Catalonia, Madrid and Navarre Community, whereas it is really low for the Canary Islands (obviously, due to its insularity), Extremadura and La Rioja. Mobility for regions as Andalusia, Aragon, Asturias or Galicia is almost balanced. Additionally, it is a bit surprising data for Cantabria and Murcia, as they are small regions but with a modern and not congested regional health care service.

Table 2. Summary statistics for $M O B$ over regions (2002-2013)

\begin{tabular}{lrrrr}
\hline & Mean & \multicolumn{1}{c}{ S.D. } & [95\% Conf. Interval] \\
\hline Andalusia & 61.23 & 6.75 & 47.91 & 74.54 \\
\hline Aragon & 59.81 & 1.80 & 56.26 & 63.36 \\
\hline Asturias & 40.32 & 1.57 & 37.24 & 43.41 \\
\hline Balearic Islands & 194.56 & 9.14 & 176.53 & 212.59 \\
\hline Canary Islands & 23.80 & 1.98 & 19.90 & 27.71 \\
\hline Cantabria & 99.61 & 5.13 & 89.50 & 109.72 \\
\hline Castile and Leon & 34.28 & 1.01 & 32.29 & 36.26 \\
\hline Castile-La Mancha & 34.28 & 1.01 & 32.29 & 36.26 \\
\hline Catalonia & 355.71 & 5.53 & 344.81 & 366.62 \\
\hline Valencian Community & 119.76 & 5.77 & 108.40 & 131.13 \\
\hline Extremadura & 14.19 & 2.22 & 9.82 & 18.56 \\
\hline Galicia & 54.09 & 0.97 & 52.18 & 56.01 \\
\hline Madrid & 381.28 & 6.12 & 369.22 & 393.34 \\
\hline Murcia & 89.79 & 5.80 & 78.35 & 101.23 \\
\hline Navarre Community & 363.01 & 19.25 & 325.05 & 400.96 \\
\hline Basque Country & 91.70 & 0.94 & 89.84 & 93.56 \\
\hline La Rioja & 31.26 & 1.56 & 28.19 & 34.32 \\
\hline
\end{tabular}

Source: Authors' calculations. 


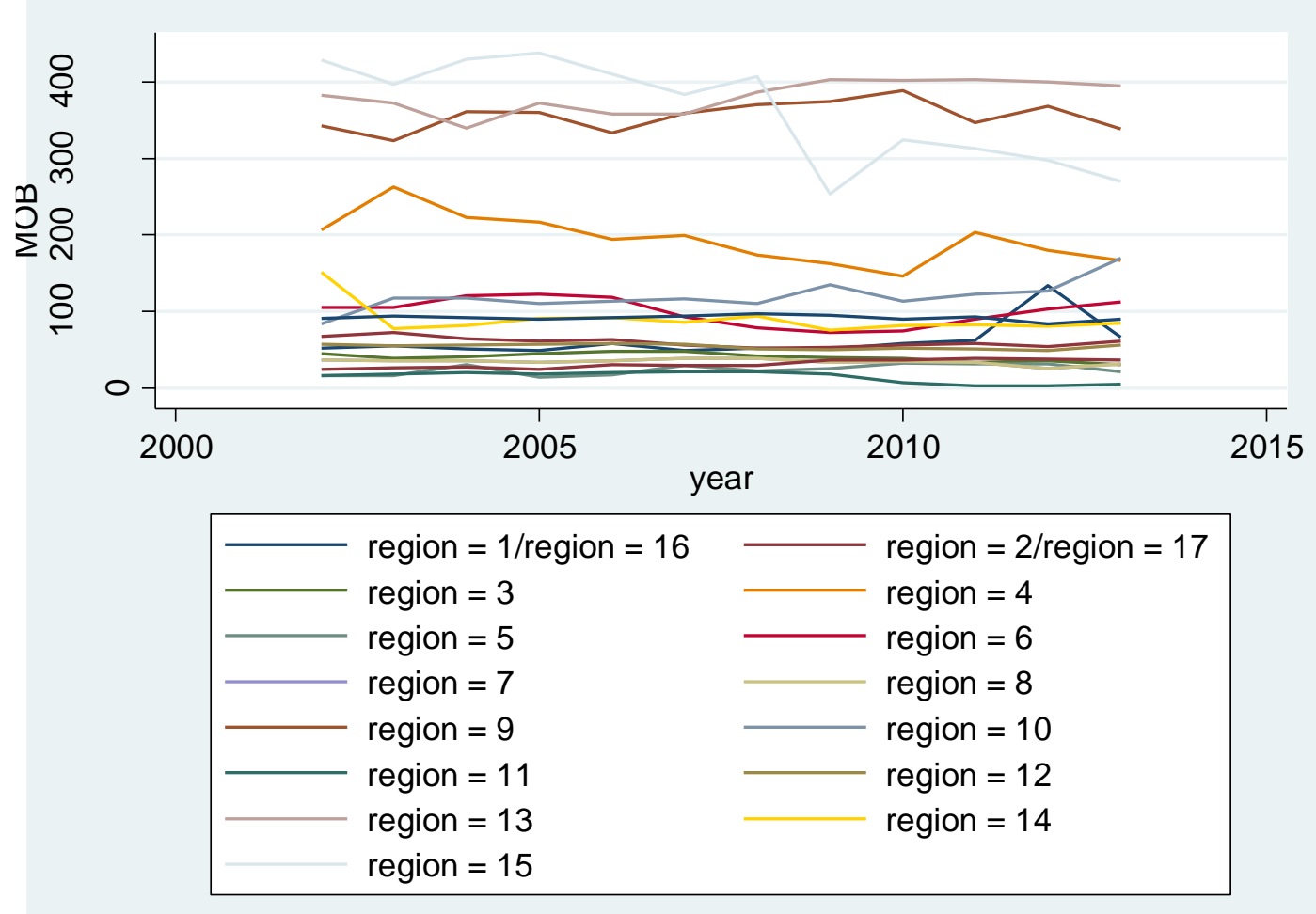

Notes: Andalusia (region =1), Aragon (region = 2), Asturias (region = 3), Balearic Islands (region = 4), Canary Islands (region $=5$ ), Cantabria (region =6), Castile and Leon (region $=7$ ), Castile-La Mancha $($ region $=8)$, Catalonia (region $=9)$, Valencian Community (region $=10)$, Extremadura (region = 11), Galicia $($ region $=12)$, Madrid (region =13), Murcia (region =14), Navarre Community (region $=15)$, Basque Country $($ region $=16)$, and La Rioja (region $=17$ ).

Figure 1. Evolution of $M O B$ by region

Source: Authors' elaboration.

Therefore, the analysis of patient's migration is done from a macroeconomic perspective on the evaluation of the effect of regional characteristics on regional net mobility in which aggregate data are considered. The inter-regional mobility is thereby based on a gravity model of migration, in which the net migration from $i$-region to the rest of Spain (" $r$ ") is a function of income and other additional attributes of the origin $i$-region and $r$ (the other regions excluding the one considered). Thus, a wide body of literature suggests that patients migrate when the perceived quality of health care in another region offsets the costs of migrating (Cantarero, 2006). Nevertheless, given the high costs of moving to a distant region, free patients' choice is actually restricted by the health care supply available to the patient and this point raises equity issues (CMPO, 2007). Also, there are several health care resources in regions so we merge all these data in each region. By including it, we consider some variables in ratio form for easier interpretation and less parameter estimation.

From the demand side, the main factors of patient choice in opting for a determined health care resource are perceived quality of services, distance from these health care resources and waiting times (Levaggi and Zanola, 2004; Fabrri and Rabone, 2010; Brenna and Spandonaro, 2015). Thus, gravity models are used to explain patient mobility across regions. In general terms, a patient will choose a health care resource in region A, with respect to a other in region $\mathrm{B}$ where he/she lives, if the cost of moving offsets the difference in quality between the two health care resources (for example, hospitals). With regard to it, health care policies have been autonomously implemented by each region within the framework of the Spanish health care setting. Precisely, as indicated by Fabbri and Robone (2010) the 
application of the gravity modelling to the issue of patient flows and hospital choice dates back to the 70s and has been updated until this date.

Hence, according to last researches the empirical migration specification equation includes variables representing ability to pay $(G D P)$, needs/preferences/individual characteristics $(P O B)$ and quality of health performance (PCHECE and lagged values of $P C H C E$ used in order to avoid problems with $G D P, B E D S$, and $M D)$, as follows:

$$
\begin{aligned}
& M O B_{i r}=\alpha_{0}+\alpha_{1}\left(\frac{G D P_{i}}{G D P_{r}}\right)+\alpha_{2}\left(\frac{P O P_{i}}{P O P_{r}}\right)+\alpha_{3}\left(\frac{P C H C E_{i}(-1)}{P C H C E_{r}(-1)}\right)+\alpha_{4}\left(\frac{B E D S_{i}}{B E D S_{r}}\right)+ \\
& +\alpha_{5}\left(\frac{M D_{i}}{M D_{r}}\right)+\varepsilon_{i} .
\end{aligned}
$$

It is important to highlight that different ratios of aged structure are considered but we maintain our specification in the analysis on mobility flows, focusing on the ageing population (as an important factor with different economic consequences (Arltová et al., 2016). Besides, in preliminary econometric analysis, we investigate the dynamic structure of the model, and we found that no additional lags of dependent variable and lagged regressors were significant.

Also, because we expect some effects in the case of regions, we analyze differences in migration between North and Mediterranean autonomous communities which are considered different in health care conditions in previous studies. Probably, patient cross-border mobility preferences can easily be changed when information on health care quality is incomplete and regional differences can extend it in order to obtain opportunistic advantages as income raises.

\section{Results}

The results of the estimated panel data model are reported in Table 3. The Hausman test for unobservable heterogeneity leads not to reject the null hypothesis. So, we have used the random effects model. Overall, a comparison of the models reported in this Table 3 indicates that the third general model outperforms the other three models in terms of goodness-of-fit, as it exhibits the higher square correlation between observed and fitted values ( 0.43 vs. 0.45 or 0.46$)$.

As we expected, our empirical findings show that the attraction power is on average higher for boundary regions for the different specifications. The hypotheses suggested by academic literature on both gravity models and quality driven mobility are confirmed too.

Also, regarding income and expenditure (in spite not being significant the latest) variables it is important to highlight that present the expected positive signs. This fact may indicate the controversial double influence of income, and how the effects could be compensated. On the one hand, it might represent ability to pay of potential migrants looking for quality. On the other hand, it should show greater ability to provide health care at the region of residence, and so, health care expenditure would be higher along the richer ones.

Moreover, variables regarding population aged structure seem not to be significant. In any case, they present the expected signs. That is, elderly people would be more prone to move to another region in order to solve their illnesses, as the chronic conditions and free time this group of people have. Specifically, working-age population would be less prone by the fact of lack-of-time and family responsibilities. In addition, this group is the one with a higher demand for health care services.

If we focus on quality-supply indicators, they would also increase the inflows (mainly through medical doctors). That is, quality-supply could be considered an important 
determinant of inter-regional mobility. Hence, there is a clear relationship between supply allocation and accessibility to health care facilities in order to lead to equal opportunities for all. These results are also sensitive to the issue that the perception of the quality of care provided by a region depends upon the ability of that autonomous community to export net flows of services. These flows, as Tiebout (1956) suggests, are very useful tools at representing the inefficiencies of the regional health systems. They are linked with both the "first generation" literature on Fiscal Federalism (which focuses on decentralized settings to maximize social welfare) and the "second-generation" ones in which the hypothesis of benevolent social planners is not considered and decentralization is mainly understood as a suitable mechanism for limiting politicians' opportunistic behavior (Oates, 2005; Weingast, 2009).

Given that, regional health care models that are not able to retain their own patients then should pay for the fixed costs of their health care resources (hospitals and health care facilities) and for the migration of their patients to other regions. This impact is particularly high in equity terms related to the possibility of a patient to move to another region, given high travel and accommodation expenses and increase as a consequence of the economic crisis and unemployment situation in Spain.

However, there appears also not to be a pattern of mobility regarding regional areas (as was almost explained by the descriptive analysis). Beyond of the influence of the universal coverage and equity in access of health care services in Spain, we really think that more attention should has been paid to the study of the factors linking patient mobility and decreased health care facilities due to the economic crisis. In this sense, a reduction in the level of income may discourage seeking medical attention and migration to avoid treatment costs although in Spain health coverage is not exactly linked to labour status and the amount of copayments are not significant related to other countries (World Bank, 2009).

Table 3. Empirical Results. Dependent variable: MOB. 2002-2013

\begin{tabular}{|c|c|c|c|c|c|c|c|c|}
\hline & \multicolumn{2}{|c|}{ Model 1} & \multicolumn{2}{|c|}{ Model 2} & \multicolumn{2}{|c|}{ Model 3} & \multicolumn{2}{|c|}{ Model 4} \\
\hline Variables & Coefficient & $t$ & Coefficient & $t$ & Coefficient & $t$ & Coefficient & $t$ \\
\hline$G D P$ & 34.07 & 3.16 & 30.47 & 2.75 & 32.05 & 2.77 & 28.39 & 2.39 \\
\hline POP65 & 5.00 & 0.50 & 15.19 & 1.36 & & & & \\
\hline CHILDREN & & & & & -8.54 & -0.92 & -14.97 & -1.54 \\
\hline YOUNG-ADULTS & & & & & -4.72 & -0.17 & -18.87 & -0.65 \\
\hline MATURE-ADULTS & & & & & -4.55 & -0.28 & -4.80 & -0.30 \\
\hline OLD-YOUNG & & & & & (omitted) & & (omitted) & \\
\hline$P C H C E(-1)$ & 0.78 & 0.16 & 1.56 & 0.32 & 0.19 & 0.04 & 0.55 & 0.11 \\
\hline$B E D S$ & 13.63 & 1.76 & -11.94 & -1.54 & -13.80 & -1.77 & -11.95 & -1.52 \\
\hline$M D$ & 5.31 & 2.67 & 5.53 & 2.82 & 5.48 & 2.73 & 5.80 & 2.92 \\
\hline NORTH & & & -56.49 & -1.00 & & & -64.19 & -1.06 \\
\hline MEDITERRANEAN & & & 52.41 & 1.00 & & & 47.55 & 0.87 \\
\hline R-square & 0.45 & & 0.46 & & 0.43 & & 0.45 & \\
\hline Hausman test result & Random-ef & fects & Random-e & ffects & Random-e & ffects & Random-e & fects \\
\hline
\end{tabular}

Source: Authors' calculation.

Moreover, the estimated dynamics are likely to have a strong influence on a polarization between the group of performing regions, which are increasingly capable of attracting more patients, and the group of the weakest ones, with growing outflows and huge 
financial problems. These considerations call for a new reform in order to get a better sustainability of the current National Health Service.

\section{Discussion}

Our findings are consistent with previous ones for the Spanish case which support the existence of a quality-driven mobility, and show mobility is mainly a question of qualitysupply factors and income. It is shown that the process of decentralization of health care competences seems not to have produced big pattern changes in mobility although additional cuts will occur in the near future and it points out the need for preventing health deterioration in vulnerable groups such as the unemployed one (Urbanos-Garrido and Lopez-Valcarcel, 2015). Besides, our results indicate that richest Spanish regions attract more patients from other regions and that the most effective pull factors are the number of beds and doctors and the diversification of the organizational structure.

The reader should note that a major strength of the study is that it uses national survey data at a regional level. However, our findings are subject to some limitations such as we need more detailed information about the decentralization process in Spain and it could be useful to get data on private health care resources and not only on those that are located in the public system. Probably, the technology endowment behaves as a pull factor and, more generally, medical admissions as a push factor but in Spain there is not available all these information in each region. However, this items need to be investigated to a greater extent.

From a policy economic perspective, this paper encourages some debates about how health care decentralization could lead to regional inequalities. Also, it is important to note that as regions are free to organize their own resources there appear differences across them mainly in complementary supply and coverage and/or access to some health care programs. Nevertheless, policy makers know that inaccessibility to health care facilities produces dissatisfaction. Besides, the infra-regional trade-off between greater patient choice (due to an increase in health care services supply) and financial equilibrium has been solved by many regions by handling patient inflows.

Thus, current regional health policies in Spain that explain patients' mobility should be accompanied with a new arrangement of an ad hoc financing system between Regional Authorities and providers in order to drive non-resident patient admissions. This opens a more general debate on whether and to what extent the Spanish health financing model would require the creation of fit equalizing compensation schemes aimed at neutralizing the budget consequences of mobility and to guarantee universalism coverage, low copayments and equity in health care.

Moreover, the last contribution of this study is to provide a framework in which to stress the importance of an accreditation policy designed to increase the quality of a regional health system and confirms that well-known health care facilities and hospitals are driving factors for patient mobility.

\section{Conclusions}

Inter-regional patients' mobility is becoming a predominant phenomenon for health care resource reallocation among countries, regions and provinces (another important fact this days would also be professional mobility and/or health workforce imbalances (Marchal and Kegels, 2003; Luboga et al., 2011). This paper contributes to recent empirical studies regarding health care migration, its determinants and patterns. Besides, when inter-regional patient mobility is considered as a long-lasting issue, financial flow imbalances across geographical areas may rise or decrease the sustainability of regional budgets. 
Specifically, a model that considers the aggregate net balance of patients' migration from the seventeen Spanish regions in the period between 2002 and 2013 is presented. In doing so, data from different sources of information is taken and we estimate a panel data based on a gravity model of migration using demographic, socioeconomic and health supply characteristics. Also, several regional dimensions have been considered. For many variables, the estimated coefficients are in line with the effects expected on the basis of the arguments presented in the paper according to health economics literature.

Econometric results indicate that health migration is mainly driven by quality factors, and that the effects of regional income and expenditure appear to be compensated. We also detect an important dynamic trend in inter-regional patient mobility over time and this finding could have serious implications for the long-run sustainability of the overall National Health Service in Spain. However, there was no significant difference in the influence on patients' mobility between those living in the North of the country and the Mediterranean regions. In particular, the results highlight that health care decentralization has not produce too many changes. Nevertheless, there exists regional externalities from neighbor regions, influencing through learning, innovation and communication processes, which negatively affect the outflows and positively affect the inflows of patients.

\section{References}

Arltová, M., Smrcka, L., Vrabcová, J. and Schönfeld, J. (2016), The ageing of the population in developed countries-the economic consequences in the Czech Republic, Economics \& Sociology, Vol. 9, No. 2, p. 197.

Arrow, K. J. (1963), Uncertainty and the welfare economics of medical care, American Economic Review, Vol. 53, No. 5, pp. 941-973.

Baker, L. C, Bundorf, M. K, Kessler, D. P. (2014), Patient's preferences explain a small but significant share of regional variation in medical spending, Health Affairs, Vol. 27, No. 2, W123-134.

Balia, S., Brau, R., Marrocu, E. (2014), Free patient mobility is not a free lunch. Lessons from a decentralised NHS, Centre for North South Economic Research, No. 201409, University of Cagliari and Sassari, Sardinia.

Brekke, K. R., Levaggi, R., Siciliani, L., Straume, O. R. (2015), Patient mobility and health care quality when regions and patients differ in income, Journal of Economic Behaviour and Organization, Vol. 105, pp. 140-157.

Brenna, E., Spandonaro, F. (2015), Regional incentives \& patient cross-border mobility: evidence from the Italian experience, International Journal of Health Policy and Management, Vol. 4, No. 6, pp. 363-372.

Cantarero, D. (2006), Health care and patients' migration across Spanish regions, European Journal of health Economics, Vol. 7, No. 2, pp. 114-116.

Centre for Market and Public Organisation (CMPO) (2007), Hospital care in England: who will choose? Research in Public Policy, University of Bristol, http://www.bristol. ac.uk/cmpo/audio/propper.html.

Congdon, P. (2001), The development of gravity models for hospital patient flows under system change: A bayesian modelling approach, Health Care Management Science, Vol. 4, pp. 289-304.

Costa-Font, J. (2010), Does devolution lead to regional inequalities in welfare activity? Environment and planning. C, Government and Policy, Vol. 28, No. 3, pp. 435-449.

Cuenca, A., González, R. (2015), Sistema de financiación autonómica y gasto sanitario en España, Papeles de Economía Española, Vol. 143, pp. 75-93. 
De Mello-Sampayo, F. (2014), Gravity for health: An application to state mental hospital admissions in Texas, MPRA Paper, No. 59758.

Exworthy, M., Peckham, S. (2006), Access, choice and travel: implication for health policy, Social Policy and Administration, Vol. 40, pp. 267-87.

Fabbri, D., Robone, S. (2010), The geography of hospital admission in a National Health Service with patient choice, Health Economics, Vol. 19, pp. 1029-1047.

Finkelstein, A., Gentzkow, M., \& Williams, H. (2016), Sources of geographic variation in health care: Evidence from patient migration, The Quarterly Journal of Economics, Vol. 131(4), pp. 1681-1726.

Frischhut, M., Levaggi, R. (2015), Patient mobility in the context of austerity and an enlarged EU: The European Court of Justice's ruling in the Petru Case, Health Policy, Vol. 119, pp. 1293-1297.

Glinos, I. A, Baeten, R., Helbe, M., Maarse, H. (2010), A typology of cross border mobility, Health and Place, Vol. 16, pp. 1145-55.

Glinos, I., Doering, N., Maarse, H. (2012), Travelling home for treatment and EU patients' right to care abroad: results of a survey among German students at Mastricht University, Health Policy, Vol. 105, pp. 38-45.

González López-Valcárcel, B., Barber, P. (2017), Economic Crisis, Austerity Policies, Health and Fairness: Lessons Learned in Spain, Applied Health Economics and Health Policy, Vol. 15(1), pp. 13-21.

Grossman, M. (1972a), The demand for health: a theoretical and empirical investigation, New York; National Bureau of Economic Research, Columbia University Press.

Grossman, M. (1972b), On the concept of health capital and the demand for health, Journal of Political economy, Vol. 80, No. 2, pp. 223-255.

Levaggi, R., Zanola, R. (2004), Patients' migration across regions: the case of Italy, Applied Economics, Vol. 36, No. 16, pp. 1751-1757.

Lopez-Casasnovas, G., Costa-Font, J., Planas, I. (2005), Diversity and regional inequalities in the Spanish system of health care services, Health Economics, Vol. 14, no. 1, S221-35.

Lowe, J. M., Sen, A. (1996), Gravity model application in health planning: analyses of an urban hospital market, Journal of Regional Sciences, Vol. 36, pp. 437-461.

Luboga, S., Hagopian, A., Ndiku, J., Bancroft, E., McQuide, P. (2011), Satisfaction, motivation, and intent to stay among Ugandan physicians: a survey from 18 national hospitals, International Journal of Health Policy and Management, Vol. 26, No. 1, pp. 2-17.

Lunt, N., Mannion, R., Exworthy, M. (2013), A framework for exploring the policy implication of UK Medical Tourism and international patient flows, Social Policy and Administration, Vol. 47, pp. 1-25.

Lunt, N., Mannion, R. (2014), Patient mobility in the global marketplace: a multidisciplinary perspective, International Journal of Health Policy and Management, Vol. 14, No. 2 , pp. 155-7.

Marchal, B., Kegels, G. (2003), Health workforce imbalances in times of globalization: brain drain or professional mobility? International Journal of Health Policy and Management, Vol. 18, S1, S89-S101.

Migge, B., Gilmartin, M. (2011), Migrants and healthcare: investigating patient mobility among migrants in Ireland, Health and Place, Vol. 17, pp. 1144-1149.

Oates, W. E. (2005), Toward a second-generation theory of fiscal federalism, International Tax and Public Finance, Vol. 12, pp. 349-373.

Rivera, B. (2004), Evidence on the relationship between public medical resources and health indicators, Journal of Economic Studies, Vol. 31, No. 2, pp. 98-111. 
Roghman, K. J. and Zastowny, T. R. (1979), Proximity as a factor in the selection of health care providers: emergency room visits compared to obstetric admissions and abortions, Social Science and Medicine, Vol. 13, pp. 61-69.

Tiebout, C. (1956), A pure theory of local expenditures, The Journal of Political Economy, Vol. 64, pp. 416-24.

Urbanos-Garrido, R. M., Lopez-Valcarcel, B. G. (2015), The influence of the economic crisis on the association between unemployment and health: an empirical analysis for Spain, The European Journal of Health Economics, Vol. 16, No. 2, pp.175-184.

Weingast, B. R. (2009), Second generation fiscal federalism: The implications of fiscal incentives, Journal of Urban Economics, Vol. 65, pp. 279-293.

World Bank (2009), Averting a human crisis during the global downturn, Washington. 